Article

\title{
Poly (Lactic-co-Glycolic Acid) Nanoparticles and Nanoliposomes for Protein Delivery in Targeted Therapy: A Comparative In Vitro Study
}

\author{
Giulia De Negri Atanasio ${ }^{1}$, Pier Francesco Ferrari ${ }^{2, *}$ (D), Roberta Campardelli ${ }^{3, *(D)}$, \\ Patrizia Perego ${ }^{3,4}$ and Domenico Palombo ${ }^{2,4,5}$ \\ 1 Department of Experimental Medicine, University of Genoa, via Leon Battista Alberti, 2, 16132 Genoa, Italy; \\ giulia.denegriatanasio@edu.unige.it \\ 2 Department of Surgical and Integrated Diagnostic Sciences, University of Genoa, viale Benedetto XV, 6, \\ 16132 Genoa, Italy; domenico.palombo@unige.it \\ 3 Department of Civil, Chemical and Environmental Engineering, University of Genoa, Via Opera Pia, 15, \\ 16145 Genoa, Italy; p.perego@unige.it \\ 4 Research Center for Biologically Inspired Engineering in Vascular Medicine and Longevity, \\ University of Genoa, via Montallegro, 1, 16145 Genoa, Italy \\ 5 Vascular and Endovascular Surgery Unit, IRCCS Ospedale Policlinico San Martino, Largo Rosanna Benzi, 10, \\ 16132 Genoa, Italy \\ * Correspondence: pier.francesco.ferrari@unige.it (P.F.F.); roberta.campardelli@unige.it (R.C.)
}

Received: 29 September 2020; Accepted: 29 October 2020; Published: 1 November 2020

check for updates

\begin{abstract}
Over the previous years, the design, development, and potential application of nanocarriers in the medical field have been intensively studied for their ability to preserve drug properties, especially their pharmacological activity, and to improve their bioavailability. This work is a comparative study between two different types of nanocarriers, poly (lactic-co-glycolic acid)-based nanoparticles and phosphatidylcholine-based nanoliposomes, both prepared for the encapsulation of bovine serum albumin as a model protein. Polymeric nanoparticles were produced using the double emulsion water-oil-water evaporation method, whereas nanoliposomes were obtained by the thin-film hydration method. Both nanocarriers were characterized by morphological analysis, particle mean size, particle size distribution, and protein entrapment efficiency. In vitro release studies were performed for 12 days at $37^{\circ} \mathrm{C}$. In order to explore a possible application of these nanocarriers for a targeted therapy in the cardiovascular field, hemolytic activity and biocompatibility, in terms of cell viability, were performed by using human red blood cells and EA.hy926 human endothelial cell line, respectively.
\end{abstract}

Keywords: cardiovascular diseases; protein drug delivery; nanocarriers; polymer-based nanosystem; lipid-based nanosystem; poly (lactic-co-glycolic acid); phosphatidylcholine; hemolysis; biocompatibility

\section{Introduction}

In recent decades, smart drug delivery systems have received an increasing attention for their ability to locally deliver bioactive molecules to diseased cells, leading to a tangible refinement of current therapeutic protocols. Although cancer therapy still remains the main target of drug delivery carriers, recently they have been taken into consideration even for the treatment of other pathologies.

Cardiovascular diseases (CVDs), i.e., peripheral arterial disease, aortic disease, coronary heart disease, stroke, and transient ischemic attack, are the major causes of death in almost all parts of the world. Besides the traditional therapeutic approaches for the management of CVDs, innovative strategies based on drug delivery carriers are also emerging [1]. Experimental studies involving the 
delivery of peptides [2], proteins, i.e., growth factors [3], nucleic acids [4], and drugs [5] have been proposed in the recent literature and could be considered as the next-generation treatments for CVDs.

In particular, among the peripheral arterial diseases, atherosclerosis plays a crucial role for its high incidence. This pathology is always related to an inflammation of the arteries caused by the accumulation of low-density lipoproteins (LDL) [6]. The macrophages present at the plaque level possess a primary role as they are responsible for the phagocytosis of oxidized LDL that induce them to become foam cells. Activated macrophages start producing numerous molecules that contribute to trigger the inflammation [7]. Although a complete inhibition of proinflammatory molecules could be beneficial in atherosclerosis, it is necessary to maintain a good balance because their activity is essential for other physiological processes. Therefore, the use of therapeutic proteins, encapsulated and directed to the plaque could represent a good compromise to treat atherosclerosis while maintaining other physiological activities.

However, the efficiency of these emerging therapeutic tools is still low due to the lack of retention of the active molecules, their inactivation during the formulation and delivery processes, especially for protein-based therapies, and also to the low fraction of therapeutics that effectively reach the targeted tissue/organ after their administration. These challenges can be overcome by encapsulating therapeutics in optimized working conditions, within appropriate carriers that protect the encapsulated molecules from any adverse conditions of the external environment, and then release them at the desired site of action at a proper dose [8].

The main factors impacting the performances of delivery systems are the loading capacity, the encapsulation efficiency, the protective behavior, the release properties, and the stability over time [9]. In the cardiovascular field, different kinds of delivery systems have been proposed in the recent literature, such as polymeric nanoparticles [10], calcium carbonate nanoparticles [11], nanoemulsions [12], solid lipid particles [13], dendrimers [14], phytosomes [15], micelles [16], liposomes [17], and microgels [18].

Polymeric nanoparticles (PNPs) have been used as potential carries for several classes of drugs, such as anticancer agents [19], antihypertensive drugs [20], immunomodulators [21], hormones [22], and biological macromolecules as peptides [23], proteins [24], and nucleic acids [25]. Over the years, a great variety of natural and synthetic polymers have been exploited for the preparation of nanoparticles. Among them, poly (lactic acid) (PLA), poly (glycolic acid) (PGA), and their copolymer, poly (lactic-co-glycolic acid) (PLGA) have been extensively investigated because of their high biodegradability and biocompatibility [26,27]. Different methods are used for PNP preparation such as nanoprecipitation [28], spray-drying [29], emulsion solvent evaporation [30], and microfluidic systems [31]. However, none of them is preferable because the properties of the obtained nanoparticles can be different. They could differ in size, stability over time, and their effectiveness of drug incorporation depends on the adopted preparation technique. The production method can also affect the kinetic of drug release from particles, which is also another important factor to be taken into account working with nanoparticles. Among the technologies proposed for PNP production, the emulsion evaporation method is the most frequently used, since it allows a better control over particle size distribution, reducing solvent residue and resulting in a high entrapment efficiency [32].

Other suitable carriers for peptides, proteins, and nucleic acids are nanoliposomes (NLPs) [33]. They are vesicles formed by an external lipid double layer and an internal aqueous core, which make them useful for the entrapment, the delivery, and the release of water-soluble, lipid-soluble, and amphiphilic compounds. NLPs have been demonstrated to deliver several substances as imaging agents [34], peptides and proteins [35], low molecular weight molecules [36], and nucleic acids [37]. Several batch-scale and a few large-scale techniques have been reported for liposome preparation giving rise to vesicles with different sizes (ranging from nanometers to several microns in diameter) and different number of bilayers. The most common preparation techniques comprise thin-film hydration, reverse phase evaporation, solvent injection, emulsion solvent evaporation, coacervation, freeze-thawing, sonication, extrusion, and high pressure methods [38,39]. Most of these techniques are not suitable for the encapsulation of sensitive molecules because of their exposure to mechanical stresses 
(e.g., sonication and high-pressure-based methods), to potentially harmful chemicals (e.g., organic solvents and detergents) or to change in $\mathrm{pH}$ during the preparation step. For all these reasons, the thin-film hydration method, which historically was the first proposed for liposome production, still remains the most currently used technique [40].

PNPs and NLPs seem to be good candidates for the delivery of proteins to treat CVDs. However, a systematic comparative study between them is still missing.

In this work, two types of nanoparticles were studied: PNPs using PLGA as polymer matrix were produced via the emulsion solvent evaporation method and NLPs were prepared starting from phosphatidylcholine (PC), following the thin-film hydration technique. Bovine serum albumin (BSA) was entrapped as model protein in these two nanosystems. The prepared nanocarriers were characterized by morphological analyses, particle mean size, particle size distribution, and entrapment efficiency. BSA release kinetic was studied for 12 days at $37^{\circ} \mathrm{C}$ for both the nanocarriers. In order to prove a potential application of these nanocarriers for a targeted therapy in cardiovascular diseases, hemolytic activity on human red blood cells and biocompatibility tests on EA.hy 926 human endothelial cell line over a period of $72 \mathrm{~h}$ were performed.

\section{Materials and Methods}

\subsection{Chemicals}

Polymeric nanoparticles (PNPs) were produced using poly (D,L-lactide-co-glycolide) 50:50 $(\mathrm{Mw}=54,000-69,000 \mathrm{~g} / \mathrm{mol}) \quad\left(\right.$ RESOMER $^{\circledR}$ RG 505, Evonik Industries, Essen, Germany). Poly (vinyl alcohol) (PVA) ( $\mathrm{Mw}=31,000-50,000 \mathrm{~g} / \mathrm{mol}$ ), bovine serum albumin (BSA), and phosphatidylcholine (PC) from egg yolk for nanoliposomes (NLPs) were supplied by Sigma-Aldrich (Saint Louis, MO, USA). Ethyl acetate and chloroform used during the preparation and all the reagents for cell culture, i.e., Dulbecco's Modified Eagle's Medium (DMEM, high glucose w/L-glutamine w/sodium pyruvate), fetal bovine serum (FBS), trypsin, and Dulbecco's Phosphate Buffered Saline w/o calcium w/o magnesium (DPBS) were purchased from Carlo Erba (Milan, Italy).

The bicinchoninic acid (BCA) protein assay kit (Euroclone, Pero, Italy) was used to quantify the proteins for calculating the encapsulation efficiency (EE) and for the in vitro release studies. CellTiter $96{ }^{\circledR}$ AQueous One Solution Cell Proliferation Assay (MTS) for cell viability studies was bought from Promega (Madison, WI, USA).

\subsection{Preparation of Polymeric Nanoparticles}

PNPs were obtained using an emulsion solvent evaporation method based on a water/oil/water $(\mathrm{w} / \mathrm{o} / \mathrm{w})$ double emulsion technique. First, the water internal phase was prepared by dissolving BSA in Milli-Q water to obtain solutions at different concentrations $(30,35$, and $40 \mathrm{mg} / \mathrm{mL})$. Then, the oil phase was prepared by dissolving $100 \mathrm{mg}$ of poly (lactic-co-glycolic acid) (PLGA) in $1.0 \mathrm{~mL}$ of ethyl acetate until its complete dissolution. The primary emulsion was obtained adding an adequate volume of the water internal phase containing BSA to the prepared oil phase. For each preparation, the water internal phase volume was calculated to achieve a PLGA to BSA ratio equal to $60 \%(w / w)$. This value was selected on the basis of a previous optimization study aimed at entrapping BSA with high efficiency [33]. The primary emulsion was obtained by ultrasonic process using a Vibra-Cell ${ }^{\mathrm{TM}}$ ultrasonic liquid processor (Sonics \& Materials, Inc., Newtown, CT, USA) with a $20 \mathrm{kHz}$ ultrasonic generator probe at $70 \%$ amplitude in pulsed mode ( $30 \mathrm{~s}$ on and $30 \mathrm{~s}$ off) for $1 \mathrm{~min}$, at room temperature $\left(25 \pm 2{ }^{\circ} \mathrm{C}\right)$. The water external phase was a PVA $(2 \%, w / v)$ water solution. A fixed amount of water external phase of $4.0 \mathrm{~mL}$ was then added to the primary emulsion. The $\mathrm{w} / \mathrm{o} / \mathrm{w}$ emulsion was prepared by sonicating the obtained mixture at the same conditions mentioned above. At the end of the second sonication process, the w/o/w emulsion was diluted up to $7.5 \mathrm{~mL}$ with the same external phase solution of PVA aforementioned. The obtained emulsion was left for at least $4 \mathrm{~h}$ under magnetic stirring at ambient conditions to allow the complete evaporation of the organic solvent. 
The obtained nanoparticle solution was then centrifuged three times at $12,984 \times g$ for $30 \mathrm{~min}$ at $4{ }^{\circ} \mathrm{C}$ (centrifuge from Alliance Bio Expertise MF-20R, Guipry, France) and the pellet was washed with deionized water to remove the excess of free BSA. After preparation, polymeric nanoparticle suspensions were stored at $4{ }^{\circ} \mathrm{C}$. Empty PNPs $\left(\mathrm{PNP}_{\mathrm{E}}\right)$ were also produced following the same procedure described above and used as control during the entire experimentation.

\subsection{Preparation of Nanoliposomes}

NLPs were produced using the thin-film hydration method. Briefly, $500 \mathrm{mg}$ of PC was dissolved in $100 \mathrm{~mL}$ of chloroform. Then, the organic solvent was removed using a rotary evaporator (model Laborota 4000, Heidolph, Schwabach, Germany). Previously, BSA was dissolved in Milli-Q water at three different concentrations $(3.0,4.0$, and $6.0 \mathrm{mg} / \mathrm{mL}$ ) and each aqueous solution was used to hydrate the obtained thin-film layer. The volume of water was always selected in order to maintain the ratio between PC and BSA equal to $60 \%(w / w)$ for comparison purposes with PNPs. The solution was left under magnetic stirring for $3 \mathrm{~h}$ at room temperature. Then, it was homogenized for 2 min using the same Vibra-Cell ${ }^{\mathrm{TM}}$ ultrasonic liquid processor reported above at the same conditions. The obtained liposome solution was then centrifuged at $12,984 \times \mathrm{g}$ for $30 \mathrm{~min}$ at $4{ }^{\circ} \mathrm{C}$ three times and the pellet was washed with deionized water to remove the non-entrapped BSA. Liposome suspensions were stored at $4{ }^{\circ} \mathrm{C}$ after preparation. Empty NLPs $\left(\mathrm{NLP}_{\mathrm{E}}\right)$ were also produced following the same procedure and used as control during the entire experimentation.

\subsection{Particles Size}

Both PNPs and NLPs were characterized using Dynamic Light Scattering (DLS) with a Zetasizer Nano ZS (Malvern Instruments Ltd, Worcestershire, UK) to measure mean diameter (MD) and particle size distribution (PSD) of the obtained carriers. This instrument worked at $25^{\circ} \mathrm{C}$ and was equipped with a $5.0 \mathrm{~mW}$ He-Ne laser operating at $633 \mathrm{~nm}$ with a scattering angle of $173^{\circ}$. For MD, at least three measurements for each sample were performed reporting their mean value \pm standard deviation (SD). In the case of PSD, it has been analyzed after particle preparation for each batch.

\subsection{Scanning Electron Microscopy}

PNP and NLP morphology was studied by using a Phenom ProX desktop SEM (Phenom-World $\mathrm{BV}$, Eindhoven, Netherlands). $\mathrm{PNP}_{\mathrm{E}}$ and $\mathrm{NLP}_{\mathrm{E}}$ were prepared as described above. Prior to being analyzed, samples were filtered by using $0.22 \mu \mathrm{m}$ pore size filters. After that, a drop of each preparation was poured over a glass slide and kept at room temperature until the complete evaporation of water. Before scanning electron microscopy (SEM) analysis, samples were sputtered with gold in the presence of argon. At least three different images for each sample were acquired.

\subsection{Entrapment Efficiency}

The BSA entrapment efficiency (EE) was calculated by an indirect method. The amount of encapsulated BSA was calculated after collection of the supernatants. In detail, both PNPs and NLPs after their preparation were centrifuged at $12,984 \times \mathrm{g}$ for $30 \mathrm{~min}$ at $4{ }^{\circ} \mathrm{C}$ and the supernatants were collected and analyzed in terms of protein content. EE was calculated according to Equation (1):

$$
\mathrm{EE}(\%)=\frac{\text { amount of initial BSA }- \text { amount of free BSA }}{\text { amount of initial BSA }} \times 100
$$

Total amount of initial BSA is referred to the BSA initially used during the preparation procedures while free BSA is the protein present in the supernatants after the centrifugation step; i.e., the non-entrapped. BSA was quantified by BCA assay following the manufacturer's instructions and the absorbance of the samples was read at $562 \mathrm{~nm}$ using a microplate reader (Tecan Spark ${ }^{\circledR} 20 \mathrm{M}$, Tecan, Männedorf, Switzerland). This analysis was performed in triplicate. 


\subsection{In Vitro Release Studies}

The in vitro release studies were performed both with PNPs and NLPs. At first, nanocarriers were centrifuged at $12,984 \times \mathrm{g}$ for $30 \mathrm{~min}$ at $4{ }^{\circ} \mathrm{C}$ with the same centrifuge reported above to remove free BSA. Then, PNPs and NLPs were resuspended in $10 \mathrm{~mL}$ of DPBS $(\mathrm{pH}=7.4)$ and stored at $37 \pm 2{ }^{\circ} \mathrm{C}$ (incubator VWR, Radnor, PA, USA) under constant stirring. For a period of 12 days at a fixed time, samples were centrifuged at $12,984 \times g$ and an amount of supernatant corresponding to $3 \%$ of the total volume was collected and replaced with the same amount of fresh DPBS. In order to calculate the protein concentration, supernatants were analyzed by using the BCA assay as mentioned before. The obtained values were expressed as percentage of released BSA over time and were determined by summing the released BSA mass at each time point. Release studies were performed in triplicate.

\subsection{Hemolysis}

The in vitro evaluation of the nanocarrier compatibility with the red blood cells (RBC) is an important preclinical test. Human blood was obtained by healthy volunteers, who have given their consent by an agreement proposed and accepted by a local ethic committee (9 March 2010) in the context of "Centro di Risorse Biologiche". Furthermore, hemolysis experiments were performed following the Guidelines of the European Community Council in accordance with the Nuremberg Code (Directive 2004/23/EC). Blood was collected into ethylenediaminetetraacetic acid (EDTA) test tubes and centrifuged for $10 \mathrm{~min}$ at $867 \times g$ (centrifuge SL 8, Thermo Fisher Scientific, Osterode, Germany) in order to separate erythrocytes from plasma [41]. Then, the obtained pellets were washed three times with DPBS while supernatants were discarded. At the end of this procedure, erythrocytes were resuspended in DPBS. Different concentrations of nanocarriers were mixed with erythrocytes to have a solution with a final volume of $150 \mu \mathrm{L}$. The solutions were then incubated, under agitation at $25^{\circ} \mathrm{C}$ (orbital shaker-incubator ES-20, Grant-bio, Grant Instruments Ltd, Shepreth, Cambridgeshire, England) for $2 \mathrm{~h}$ and then centrifuged for $5 \mathrm{~min}$ at $867 \times g$ (centrifuge Z 216 MK, HERMLE Labortechnik GmbH, Wehingen, Germany). The obtained supernatants were spectrophotometrically analyzed at $540 \mathrm{~nm}$ using the plate reader reported before. The hemolysis percentage was calculated using Equation (2):

$$
\text { Hemolysis }(\%)=\frac{\mathrm{Abs}_{\mathrm{s}}-\mathrm{Abs}_{\mathrm{n}}}{\mathrm{Abs}_{\mathrm{p}}-\mathrm{Abs}_{\mathrm{n}}} \times 100
$$

where:

$\mathrm{Abs}_{\mathrm{s}}$ : is the absorbance of the sample;

$\mathrm{Abs}_{\mathrm{n}}$ : is the absorbance of the negative control;

$\mathrm{Abs}_{\mathrm{p}}$ : is the absorbance of the positive control.

The negative and the positive controls were obtained treating erythrocytes with DPBS and deionized water, respectively [42]. For this test, the concentration of the particles to be used was calculated on the basis of the amount of entrapped BSA. Negative results were approximated to zero in the analysis and statistical studies were performed exclusively for samples showing a hemolysis percentage lower than 5 .

\subsection{Cell Viability}

EA.hy926 human endothelial cells (ATCC ${ }^{\circledR}$ CRL-2922 ${ }^{\mathrm{TM}}$ ) were cultured in DMEM supplemented with $10 \%(v / v)$ of $\mathrm{FBS}$ and incubated at $37^{\circ} \mathrm{C}$ and $5 \% \mathrm{CO}_{2}$ until $70 \%$ confluency was reached. $4 \times 10^{3}$ cells were seeded in each well of a 96-well plate and incubated overnight before any treatments. Cells were treated with different concentrations $\left(0.1,1.0,10,100,200,300\right.$, and $\left.500 \mu \mathrm{g}_{\mathrm{BSA}} / \mathrm{mL}\right)$ of both empty and loaded PNPs and NLPs. After 24, 48, and $72 \mathrm{~h}$ of incubation with PNPs and NLPs, cell viability was quantified by CellTiter $96^{\circledR} A Q_{\text {ueous }}$ One Solution Cell Proliferation Assay (MTS). Daily, the medium of analyzing well was discarded, cells were washed with DPBS, and a mix of fresh medium (100 $\mu \mathrm{L})$ and 
reagent $(20 \mu \mathrm{L})$ was added to each well and incubated for three hours. At the end of the incubation time, the absorbance of the samples was read at $490 \mathrm{~nm}$ by using the same plate reader indicated above. For this test, the concentration of the particles to be used was calculated on the basis of the amount of the entrapped BSA. For PNP $\mathrm{E}_{\mathrm{E}}$ and $\mathrm{NLP}_{\mathrm{E}}$, an equal amount of the BSA-loaded PNPs and NLPs, respectively, was used for each investigated concentrations. Controls were represented by untreated endothelial cells (without nanoparticles). All the experiments were performed in triplicate and results were expressed as a percentage with respect to the control (100\%).

\subsection{Statistical Analysis}

All the experiments were done at least in triplicate and the results are expressed as mean values \pm standard deviation. Statistical analysis was done by one-way analysis of variance (ANOVA), following Tukey's HSD post hoc multiple comparison test using Statistica v 8.0 software (StatSoft, Tulsa, OK, USA).

\section{Results}

\subsection{Production and Characterization of BSA-Loaded Nanocarriers}

Both PNPs and NLPs were successfully loaded with BSA with remarkable differences between them. For the production of PNPs, a protocol based on w/o/w emulsion was adopted. The volume of the internal water phase, when this technique is applied, represents an important parameter which affects entrapment efficiency (EE). The required volume of the internal aqueous phase is mainly determined by the solubility of the compound that has to be encapsulated and it influences particle structure and therefore also the EE [43]. In this work, for the preparation of PNPs, the effect of the variation of the internal aqueous phase volume on mean diameter (MD), particle size distribution (PSD) and EE was studied, maintaining equal to $60 \%(w / w)$ the theoretical BSA loading with respect to PLGA or PC mass. Specifically, for PNPs it was used an internal volume of water equal to 2.00,1.70, and $1.50 \mathrm{~mL}$ and the concentration of BSA solution was 30,35, and $40 \mathrm{mg} / \mathrm{mL}$, respectively. Particles prepared without BSA $\left(\mathrm{PNP}_{\mathrm{E}}\right)$ were considered as control and taken into account for comparison purposes.

Produced PNPs showed a MD between $170 \pm 12$ and $204 \pm 20 \mathrm{~nm}$. In Table 1 and in Figure 1A it has been reported that particle MD slightly increased at higher water internal phase volumes. Figure $1 \mathrm{~A}$ highlights also a good control over PSD in all cases, particularly at the lowest water internal phase volume. In the case of PNPs, Table 1 shows a very high EE, up to $98.01 \pm 0.05 \%$. The EE slightly increased when the water internal phase volume was reduced. Probably, an increase in the water internal phase volume induces BSA losses towards the external water phase [44]. A higher volume of the internal aqueous phase can induce a decrease in the thickness of the particle polymeric layers allowing the migration of the water internal phase towards the water external phase [45]. The best condition for PNP production with good control of nanoparticle dimensions and high EE was at $1.5 \mathrm{~mL}$ of water volume with a BSA concentration of $40 \mathrm{mg} / \mathrm{mL}$.

NLPs were produced using the thin-film hydration method coupled with sonication. In this method, a lipidic layer is produced and then it is hydrated using a water solution containing the molecules of interest, in this case BSA. Spontaneous formation of liposomes is obtained thanks to favorable interactions between water and phospholipids. When liposomes structure is formed, part of the water solution used for hydration is entrapped in the vesicles. The EE is markedly related to the amount of water that is effectively entrapped in the lipid bilayer, with respect to the total amount of solution used for hydration. Therefore, the amount of hydration water is a crucial parameter affecting EE.

For this reason, for NLP production the effects of hydration water volume on liposome MD, PSD and EE were studied. Hydration volume was varied from 50 to $100 \mathrm{~mL}$, changing the BSA concentration from 6.0 to $3.0 \mathrm{mg} / \mathrm{mL}$ and keeping constant at $60 \%(w / w)$ the BSA loading with respect to PC amount. Empty NLPs $\left(\mathrm{NLP}_{\mathrm{E}}\right)$, without BSA, were produced for comparison purposes. Operating process parameters and data referred to MD and EE of NLPs are reported in Table 1. It can be 
observed that NLPs were successfully produced with MD ranging from $130 \pm 51$ to $144 \pm 60 \mathrm{~nm}$ by increasing the concentration of BSA in the stock solution used for their preparation. Figure 1B reports obtained PSD of liposomes produced with different water hydration volumes. From Table 1 and from Figure 1B, it can be noticed an increase of liposome MD when higher hydration water volume was used. PSD data, showed in Figure 1B, showed also a good control of liposome dimensions in all the studied cases. Data reported in Table 1 showed remarkable differences in EE values between PNPs and NLPs. The samples produced with 100 and $75 \mathrm{~mL}$ of hydration water showed an EE of $46.14 \pm 14.17$ and $49.49 \pm 2.18 \%$, respectively. Conversely, by reducing the hydration volume at $50 \mathrm{~mL}$ and using a more BSA concentrated solution in order to have the $60 \%$ of theoretical loading, higher EE was obtained $(80.16 \pm 7.46 \%)$. This result is in agreement with the related literature. By increasing the water hydration volume and fixing the PC content, less PC was available for unit of water, reducing the probability of entrapment of the water volume.

Table 1. Particle mean diameter and encapsulation efficiency of BSA-loaded nanocarrier prepared under different conditions. Results are expressed as mean \pm standard deviation. Different letters $(a, b$, and $\mathrm{c}$ for PNPs) and ( $\mathrm{d}$ and e for NLPs) reported in the EE column refer to statistically significant differences among the three different samples for each type of carrier $(p<0.05)$ by ANOVA with Tukey's HSD post hoc multiple comparison test. BSA: bovine serum albumin, MD: mean diameter, SD: standard deviation, EE: entrapment efficiency, PNPs: polymeric nanoparticles, NLPs: nanoliposomes.

\begin{tabular}{ccccc}
\hline & $\begin{array}{c}\text { BSA Concentration } \\
(\mathbf{m} / \mathbf{m L})\end{array}$ & $\begin{array}{c}\text { Water Internal Phase Volume } \\
(\mathbf{m L})\end{array}$ & $\begin{array}{c}\text { MD } \pm \text { SD } \\
(\mathbf{n m})\end{array}$ & EE \pm SD (\%) \\
\hline \multirow{4}{*}{ PNPs } & 0 & 1.7 & $204 \pm 20$ & - \\
& 30 & 2.0 & $195 \pm 11$ & $97.15 \pm 0.07^{\mathrm{a}}$ \\
& 35 & 1.7 & $185 \pm 10$ & $97.82 \pm 0.07^{\mathrm{b}}$ \\
& 40 & 1.5 & $170 \pm 12$ & $98.01^{\mathrm{c}} \pm 0.05^{\mathrm{c}}$ \\
\hline \multirow{4}{*}{ NLPs } & 0 & 75 & $130 \pm 51$ & - \\
& 3 & 100 & $175 \pm 62$ & $46.14 \pm 14.17^{\mathrm{d}}$ \\
& 4 & 75 & $152 \pm 68$ & $49.49 \pm 2.18^{\mathrm{d}}$ \\
& 6 & 50 & $144 \pm 60$ & $80.16 \pm 7.46^{\mathrm{e}}$ \\
\hline
\end{tabular}

The best condition for NLP production with good control over liposome dimensions and high EE was at $50 \mathrm{~mL}$ of water hydration volume with a BSA concentration of $6 \mathrm{mg} / \mathrm{mL}$.

Taking into account the two proposed nanosystems, EE was higher in the case of PNPs. The highest EE value $(98.01 \pm 0.05 \%)$ was obtained working with $1.5 \mathrm{~mL}$ of water internal phase and a final BSA concentration in the water solution equal to $40 \mathrm{mg} / \mathrm{mL}$. Figure 1A,B report PSD of PNPs and NLPs, respectively. The loading of BSA did not interfere with PSD.
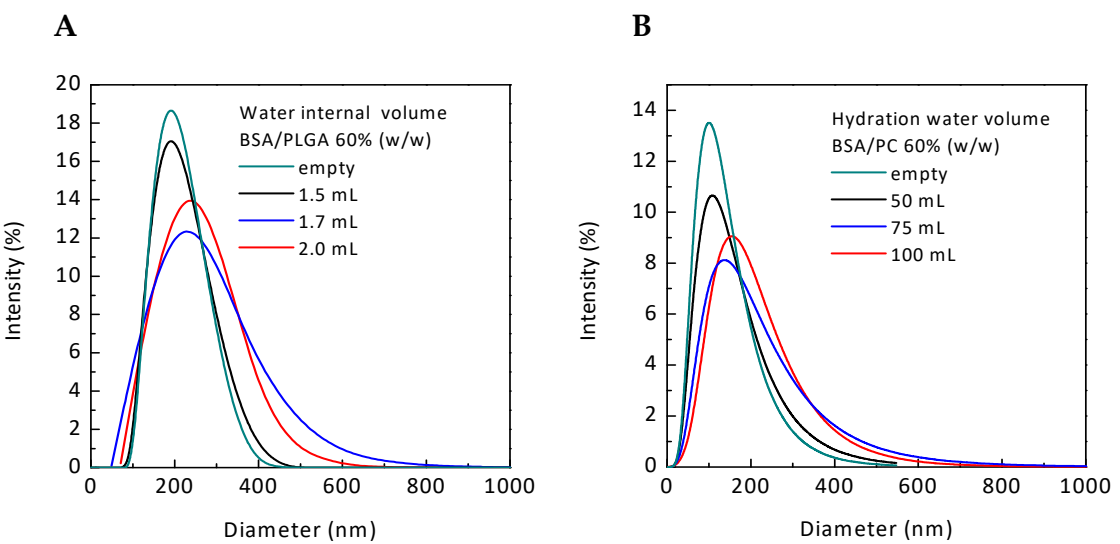

Figure 1. Representative particle size distribution of (A) PNPs and (B) NLPs. PNPs: polymeric nanoparticles, NLPs: nanoliposomes. 
As reported in Figure 2, the analyses of the morphological properties of empty PNPs and NLPs were performed using SEM. The studied nanocarriers appeared to show a spherical, well-defined morphology.
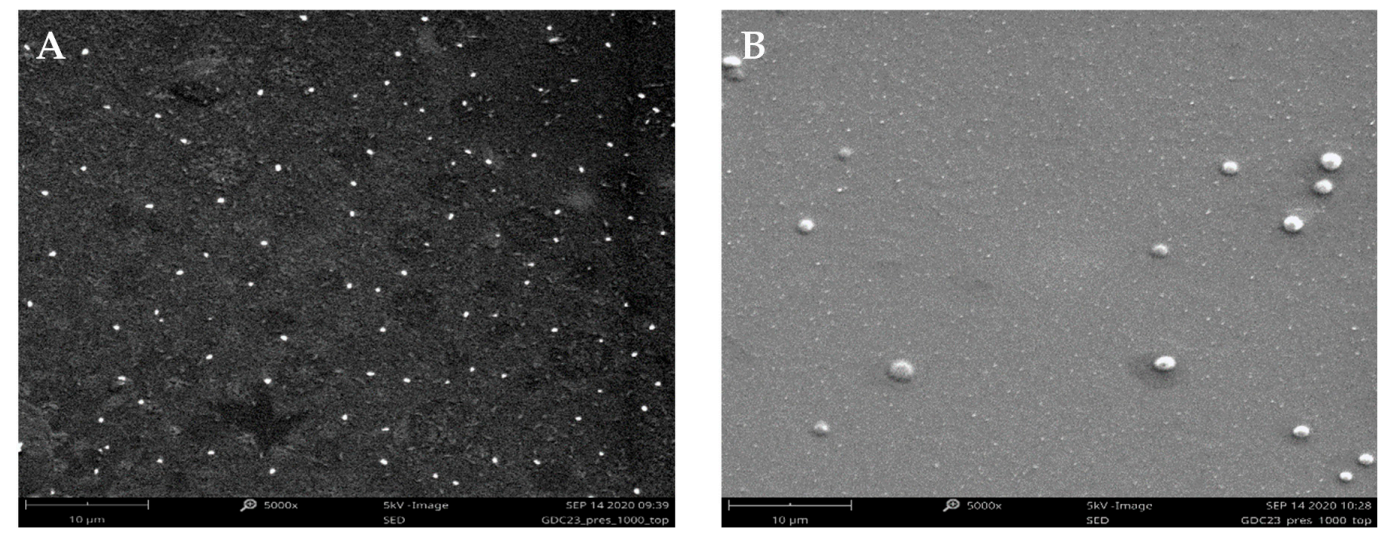

Figure 2. Representative SEM images of $(A) P_{N} P_{E}$ and (B) $N_{E} P_{E}$. SEM: scanning electron microscopy, $\mathrm{PNP}_{\mathrm{E}}$ : empty polymeric nanoparticles, $\mathrm{NLP}_{\mathrm{E}}$ : empty nanoliposomes.

\subsection{In Vitro Release Studies}

In vitro release of BSA was studied at $37^{\circ} \mathrm{C}$ over a period of 12 days. The three different release curves obtained in the case of PNPs were compared with the three curves obtained working with NLPs. During this time, the maximum amount of BSA released from PNPs and NLPs was $11.01 \pm 0.14 \%$ and $4.52 \pm 0.01 \%$, respectively (Figure $3 \mathrm{~A}, \mathrm{~B}$ ). This sustained release of the encapsulated bioactive compounds is desirable when they have to reach a pathological site transported by nanocarriers. The delay that is evident in the release of the entrapped molecule is necessary for the nanoparticles to be internalized by the cells. In fact, once they are uptaken by cells, the carriers are able to release the encapsulated molecule that will start its therapeutic effects acting on specific cellular targets. A burst release is not desirable, as it would cause leakage before reaching the target of the pathological site. Working with both the nanoparticles, a burst released of BSA was avoided in all the cases, due to the physicochemical properties of the coating agents, PLGA and PC.

A

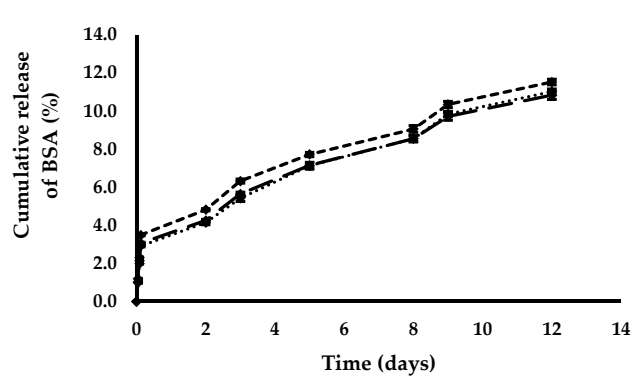

B

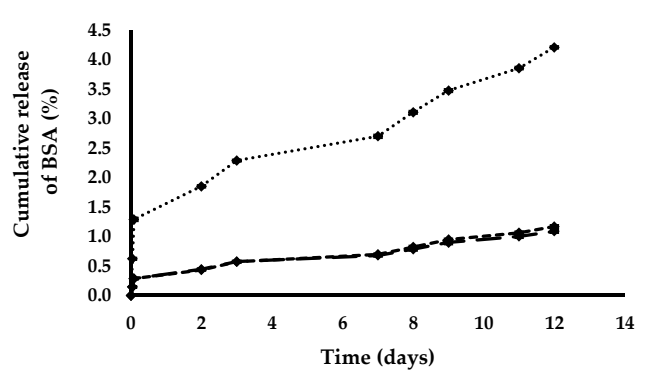

Figure 3. Release profile of BSA from (A) PNPs: $\mathrm{PNP}_{\mathrm{BSA}}(30 \mathrm{mg} / \mathrm{mL}), \boldsymbol{- - 0} \mathrm{PNP}_{\mathrm{BSA}}(35 \mathrm{mg} / \mathrm{mL})$,

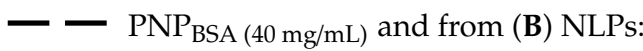
- $\mathrm{NLP}_{\mathrm{BSA}}(3 \mathrm{mg} / \mathrm{mL}), \boldsymbol{- - - - -} \mathrm{NLP}_{\mathrm{BSA}}(4 \mathrm{mg} / \mathrm{mL})$,

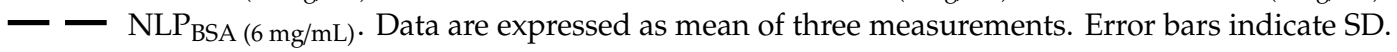
BSA: bovine serum albumin, PNPs: polymeric nanoparticles, NLPs: nanoliposomes.

\subsection{Hemolysis Assay}

Measuring hemolysis provides fast and valuable information of the effect of nanocarrier intravenous injections would have on red blood cell (RBC) membrane integrity. All the fabricated particles (PNPs and NLPs) were studied using fixed concentrations of 500, 300, 200, 100, 10, 1, and $0.1 \mu \mathrm{g}_{\mathrm{BSA}} / \mathrm{mL}$. The concentration of nanoparticles was considered in terms of BSA content. All the produced samples reported in Table 1 were tested. 
The obtained results showed that the hemolysis was higher in the presence of NLPs in comparison to PNPs, testing the same concentration. Working with both the studied nanocarriers, there was a direct correlation between the concentration of the payload and the toxicity on the erythrocytes. Figure 4A shows that in the case of $\mathrm{PNP}_{\mathrm{E}}$, there was a direct correlation between hemolysis percentage and PNP concentrations, especially for the concentration of 500, 300, and $200 \mu \mathrm{g}_{\mathrm{BSA}} / \mathrm{mL}$. Regarding the BSA-loaded PNPs, among all the different nanoparticle samples, $500 \mu \mathrm{g}_{\mathrm{BSA}} / \mathrm{mL}$ resulted to have a higher hemolytic activity in comparison with the same concentration of the $\operatorname{PNP}_{\mathrm{E}}(p<0.05)$. Furthermore, the hemolytic activity of PNP produced at BSA concentration in the water internal solution of $40 \mathrm{mg} / \mathrm{mL}$ $\left(\mathrm{PNP}_{\mathrm{BSA}}(40 \mathrm{mg} / \mathrm{mL})\right.$ ) was higher even at the concentrations of 300 and $200 \mu \mathrm{g}_{\mathrm{BSA}} / \mathrm{mL}$. For all the tested samples, a hemolytic activity lower than $5 \%$ was reported and the formulated PNPs can be considered non-hemolytic at the tested concentrations [46].

A

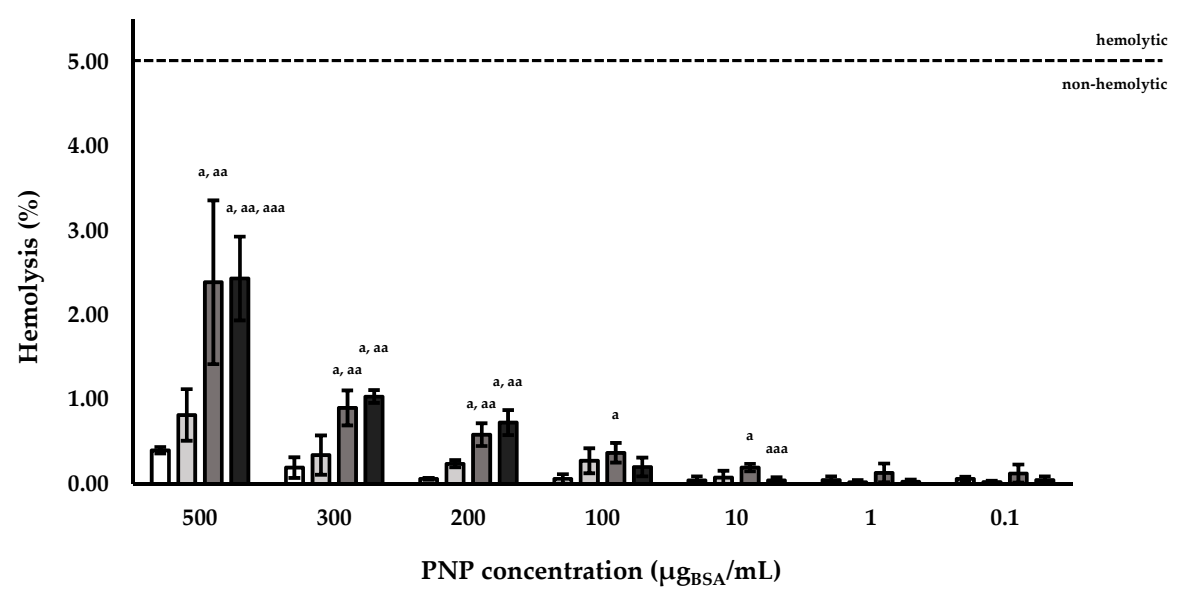

B

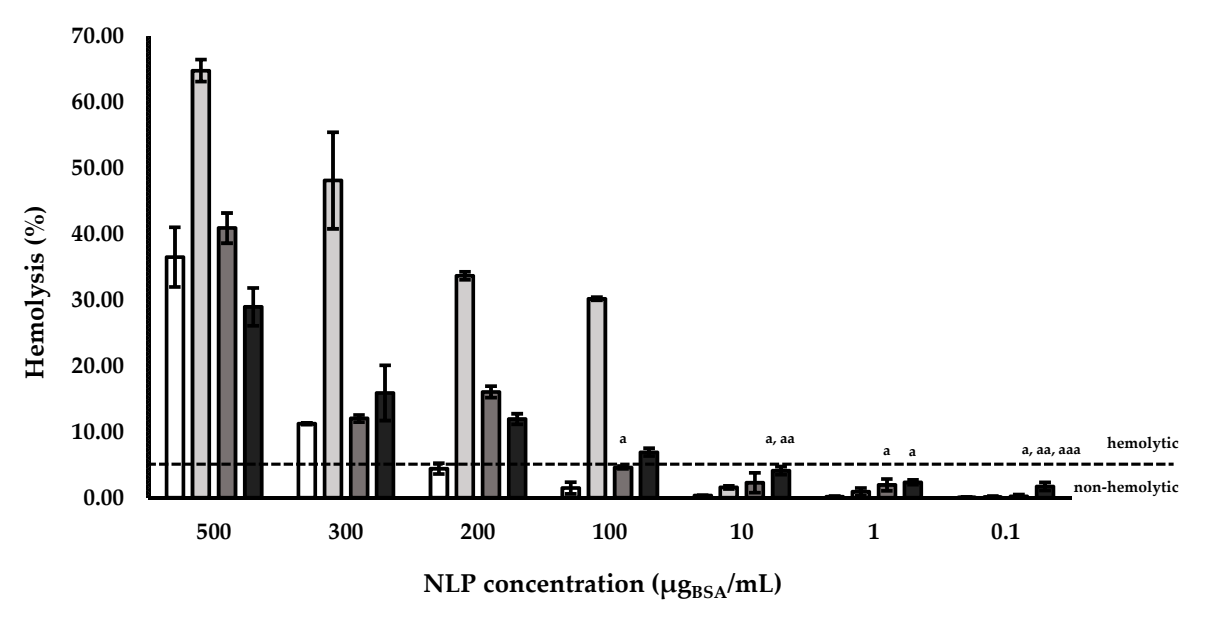

Figure 4. Hemolysis percentage of RBCs after contact with different concentrations of (A) PNPs:

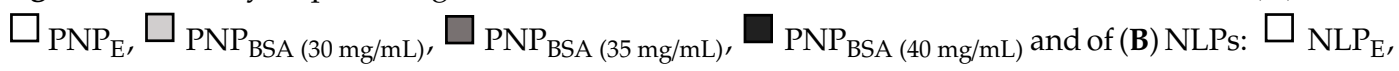

$\mathrm{NLP}_{\mathrm{BSA}(3 \mathrm{mg} / \mathrm{mL})}, \square_{\mathrm{NLP}} \mathrm{BSA}_{(4 \mathrm{mg} / \mathrm{mL})} \boldsymbol{D}_{\mathrm{NLP}_{\mathrm{BSA}}(6 \mathrm{mg} / \mathrm{mL}) \text {. RBCs: red blood cells, PNP }}$ : empty polymeric nanoparticles, $\mathrm{PNP}_{\mathrm{BSA}}$ : BSA-loaded polymeric nanoparticles, $\mathrm{NLP}_{\mathrm{E}}$ : empty nanoliposomes, $\mathrm{NLP}_{\mathrm{BSA}}$ : BSA-loaded nanoliposomes. Data are expressed as mean of three measurements. Error bars indicate SD. Different symbols refer to statistically significant differences among results $(p<0.05$, ANOVA with Tukey's HSD post hoc multiple comparison test). ${ }^{\text {a}}$ : statistically different to empty nanocarriers $\left(\mathrm{PNP}_{\mathrm{E}}\right.$ or $\left.\mathrm{NLP}_{\mathrm{E}}\right)$, aa: statistically different to $\mathrm{PNP}_{\mathrm{BSA}}(30 \mathrm{mg} / \mathrm{mL})$ or $\mathrm{NLP}_{\mathrm{BSA}}(3 \mathrm{mg} / \mathrm{mL})$, aaa: statistically different to PNP $\mathrm{BSA}_{(35 \mathrm{mg} / \mathrm{mL})}$ or $\mathrm{NLP}_{\mathrm{BSA}}(4 \mathrm{mg} / \mathrm{mL})$. The dotted line refers to $5 \%$ of hemolysis. 
Conversely, NLPs showed a hemolytic behavior, even for the empty sample at different concentrations. Concentrations of NLPs equal to 500, 300, and $200 \mu \mathrm{g}_{\mathrm{BSA}} / \mathrm{mL}$ presented a hemolysis percentage over 5 (Figure 4B). This trend was reported even in the case of BSA-loaded NLPs, but in addition for the loaded liposomes also $100 \mu \mathrm{g}_{\mathrm{BSA}} / \mathrm{mL}$ concentration presented a hemolysis percentage over 5 . The higher values of hemolysis reported for NLPs were probably caused by oxidation of their lipidic layer.

\subsection{Cell Viability}

Carriers can be considered as new therapeutic strategy only if they are biocompatible. In this work, biocompatibility was studied in terms of cell viability. Once injected in the body, nanoparticles get immediately in contact with blood and endothelial cells. For this reason, the cell viability of the two studied nanocarriers was assessed on human endothelial cells EA.hy926 by using MTS assay (Figure 5). PNPs obtained with the lower water internal phase volume of $1.5 \mathrm{~mL}$ and BSA concentration of $40 \mathrm{mg} / \mathrm{mL}$ $\left(\mathrm{PNP}_{\mathrm{BSA}}(40 \mathrm{mg} / \mathrm{mL})\right)$ were assayed. In the case of NLPs, those obtained with $50 \mathrm{~mL}$ of hydration volume and $6 \mathrm{mg} / \mathrm{mL}$ of BSA concentration $\left(\mathrm{NLP}_{\mathrm{BSA}}(6 \mathrm{mg} / \mathrm{mL})\right.$ ) were chosen. These two samples were chosen since $\mathrm{PNP}_{\mathrm{BSA}(40 \mathrm{mg} / \mathrm{mL})}$ and NLP $\mathrm{BSA}_{(6 \mathrm{mg} / \mathrm{mL})}$ represented the best compromise between the BSA release and the above-reported hemolytic properties among all the different prepared samples. They represent also the best condition for BSA EE and possess a good control over MD and PSD.

PNPs

A

$24 \mathrm{~h}$

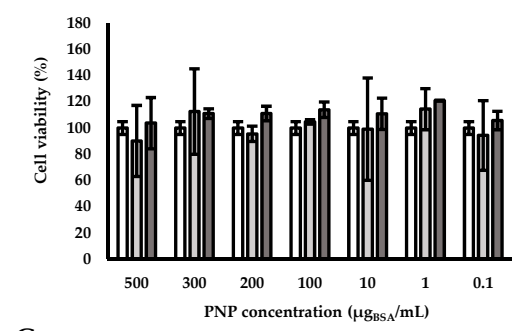

C

$48 \mathrm{~h}$

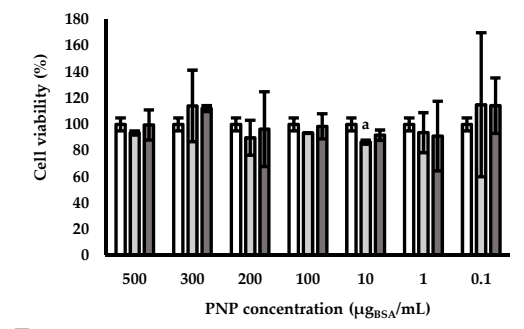

E

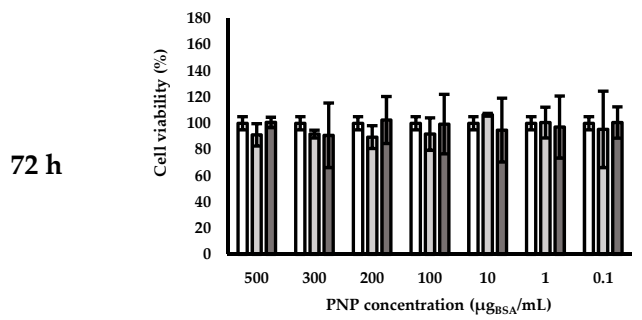

NLPs

B

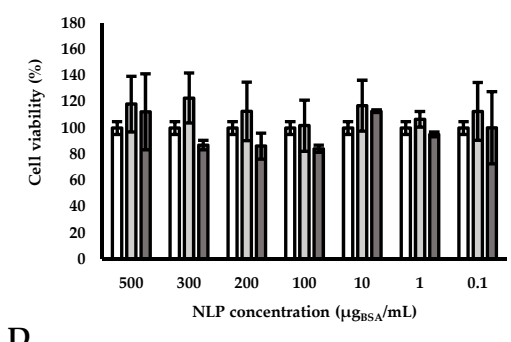

D
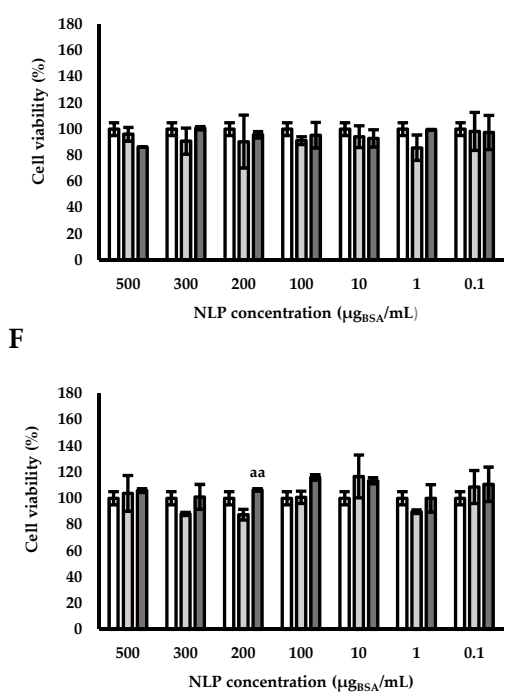

Figure 5. Cell viability of PNPs and NLPs by MTS assay after (A,B) 24, (C,D) 48, and (E,F) $72 \mathrm{~h}$. $\square$ control (without particles), $\square \operatorname{PNP}_{\mathrm{E}}(\mathbf{A}, \mathbf{C}, \mathbf{E}), \square \operatorname{PNP}_{\mathrm{BSA}(40 \mathrm{mg} / \mathrm{mL})}(\mathbf{A}, \mathbf{C}, \mathbf{E}), \square \operatorname{NLP}_{\mathrm{E}}(\mathbf{B}, \mathbf{D}, \mathbf{F})$,

$\mathrm{NLP}_{\mathrm{BSA}}(3 \mathrm{mg} / \mathrm{mL})(\mathbf{B}, \mathbf{D}, \mathbf{F})$. PNP $_{\mathrm{E}}$ : empty polymeric nanoparticles, $\mathrm{PNP}_{\mathrm{BSA}}$ : BSA-loaded polymeric nanoparticles, $\mathrm{NLP}_{\mathrm{E}}$ : empty nanoliposomes, $\mathrm{NLP}_{\mathrm{BSA}}$ : BSA-loaded nanoliposomes. Data are expressed as mean of three measurements. Error bars indicate SD. Different symbols refer to statistically significant differences among results ( $p<0.05$, ANOVA with Tukey's HSD post hoc multiple comparison test). ${ }^{a}$ : statistically different to control, ${ }^{\text {aa }}$ : statistically different to empty carrier. 
PNPs revealed to have a good biocompatibility for all the tested concentrations $(0.1,1.0,10$, $100,200,300$, and $\left.500 \mu \mathrm{g}_{\mathrm{BSA}} / \mathrm{mL}\right)$ and for all the duration of the experimentation $(24,48$, and $72 \mathrm{~h})$. No statistical differences were observed between the untreated (control) and the cells treated with PNPs for all the tested concentrations both for empty and for BSA-loaded nanocarriers. Similar results were obtained working with NLPs. No significant statistically differences were highlighted when comparing cells treated with the same concentration of NLPs over time (24, 48, and $72 \mathrm{~h})$. Furthermore, none of the tested NLP concentration caused any significant statistically decrease in cell viability at each time point. For both PNPs and NLPs, no statistically significant differences were noticed among different concentrations of the same nanocarriers at the same time point, among different time points at the same concentration for and between empty nanocarriers and loaded nanocarriers at a given concentration and a given time-point. The only exceptions were the statistically differences between control and $\mathrm{PNP}_{\mathrm{E}}$ at $10 \mu \mathrm{g}_{\mathrm{BSA}} / \mathrm{mL}$ after $48 \mathrm{~h}$ of treatment (Figure $5 \mathrm{C}$ ) and between $\mathrm{NLP}_{\mathrm{E}}$ and $\mathrm{NLP}_{\mathrm{BSA}}(6 \mathrm{mg} / \mathrm{mL})$ at $200 \mu \mathrm{g}_{\mathrm{BSA}} / \mathrm{mL}$ after $72 \mathrm{~h}$ of treatment (Figure $5 \mathrm{~F}$ ).

\section{Conclusions}

In this work, poly (lactic-co-glycolic acid)-based nanoparticles (PNPs) and phosphatidylcholine-based nanoliposomes (NLPs) were produced by a solvent emulsification evaporation method, based on a water/oil/water double emulsion technique, and a thin-film hydration method, respectively. Bovine serum albumin (BSA) was chosen as model protein to be easily replaced by specific therapeutic proteins useful for CVD treatment and was successfully encapsulated in both PNPs and NLPs, varying the volume of the internal aqueous phase. The two studied nanocarriers showed comparable mean size, particle size distribution, and morphological properties in terms of dimension and overall 3D structure. PNPs showed higher entrapment efficiencies presenting a maximum value of $98.01 \pm 0.05 \%$. Regarding BSA release, the two studied nanocarriers showed a different release profile: PNPs have released $11.53 \pm 0.06 \%$ while NLPs have released $4.61 \pm 0.02 \%$ of the encapsulated BSA after 12 days. In both the cases, considering the amount of released BSA, a burst release of the entrapped protein was avoided. The obtained results show that all the studied concentrations of PNPS have not induced erythrocyte membrane damages. Unlike PNPs, NLPs presented a hemolytic activity at all the concentrations higher than $10 \mu \mathrm{g}_{\mathrm{BSA}} / \mathrm{mL}$. Both PNPs and NLPs showed a comparable biocompatibility with human endothelial cells. On the basis of the obtained data, the choice of the better nanosystem strictly depends on the PNPs or NLPs final application. However, the studied nanocarriers can be considered as a good template to be engineered with antibodies on their surface in order to be employed in the vascular field as a nanosystem for protein drug delivery.

Future perspectives of this work will involve the engineering of the produced carriers by the decoration of the particle surfaces with specific antibodies to impart a peculiar targeting for atheromatous sites.

Author Contributions: Conceptualization, P.P. and D.P.; methodology, G.D.N.A., P.F.F., and R.C.; investigation, G.D.N.A., P.F.F., and R.C.; resources, P.P. and D.P.; data curation, G.D.N.A., P.F.F., and R.C.; writing-original draft preparation, G.D.N.A., P.F.F., and R.C.; writing—review and editing, G.D.N.A., P.F.F., R.C., P.P., and D.P.; supervision, P.P. and D.P.; project administration, P.P. and D.P.; funding acquisition, P.P. and D.P. All authors have read and agreed to the published version of the manuscript.

Funding: This work was supported by Fondi di Ricerca di Ateneo (FRA) 2018 provided by University of Genoa.

Acknowledgments: The authors acknowledge Antonio Barbucci from University of Genoa for his assistance and support during scanning electron microscopy analyses.

Conflicts of Interest: The authors declare no conflict of interest. 


\section{References}

1. Maheshwari, R.; Tekade, M.; Sharma, P.; Tekade, R. Nanocarriers assisted siRNA gene therapy for the management of cardiovascular disorders. Curr. Pharm. Des. 2015, 21, 4427-4440. [CrossRef] [PubMed]

2. Auwal, S.M.; Zarei, M.; Tan, C.; Basri, M.; Saari, N. Improved in vivo efficacy of anti-hypertensive biopeptides encapsulated in chitosan nanoparticles fabricated by ionotropic gelation on spontaneously hypertensive rats. Nanomaterials 2017, 7, 421. [CrossRef] [PubMed]

3. Oduk, Y.; Zhu, W.; Kannappan, R.; Zhao, M.; Borovjagin, A.V.; Oparil, S.; Zhang, J. VEGF nanoparticles repair the heart after myocardial infarction. Am. J. Physiol. Heart Circ. Physiol. 2018, 314, H278-H284. [CrossRef] [PubMed]

4. Theoharis, S.; Krueger, U.; Tan, P.H.; Haskard, D.O.; Weber, M.; George, A.J.T. Targeting gene delivery to activated vascular endothelium using anti E/P-Selectin antibody linked to PAMAM dendrimers. J. Immunol. Methods 2009, 343, 79-90. [CrossRef] [PubMed]

5. Chan, J.M.; Rhee, J.-W.; Drum, C.L.; Bronson, R.T.; Golomb, G.; Langer, R.; Farokhzad, O.C. In vivo prevention of arterial restenosis with paclitaxel-encapsulated targeted lipid-polymeric nanoparticles. Proc. Natl. Acad. Sci. USA 2011, 108, 19347-19352. [CrossRef]

6. Olofsson, P.S.; Söderström, L.Å.; Wågsäter, D.; Sheikine, Y.; Ocaya, P.; Lang, F.; Rabu, C.; Chen, L.; Rudling, M.; Aukrust, P.; et al. CD137 is expressed in human atherosclerosis and promotes development of plaque inflammation in hypercholesterolemic mice. Circulation 2008, 117, 1292-1301. [CrossRef] [PubMed]

7. Fava, C.; Montagnana, M. Atherosclerosis is an inflammatory disease which lacks a common anti-inflammatory therapy: How human genetics can help to this issue. A narrative review. Front. Pharmacol. 2018, 9, 1-9. [CrossRef] [PubMed]

8. Putney, S.D. Encapsulation of proteins for improved delivery. Curr. Opin. Chem. Biol. 1998, 2, 548-552. [CrossRef]

9. Perry, S.L.; McClements, D.J. Recent advances in encapsulation, protection, and oral delivery of bioactive proteins and peptides using colloidal systems. Molecules 2020, 25, 1161. [CrossRef]

10. Giannouli, M.; Karagkiozaki, V.; Pappa, F.; Moutsios, I.; Gravalidis, C.; Logothetidis, S. Fabrication of quercetin-loaded PLGA nanoparticles via electrohydrodynamic atomization for cardiovascular disease. Mater. Today-Proc. 2018, 5, 15998-16005. [CrossRef]

11. Ferrari, P.F.; Aliakbarian, B.; Zattera, E.; Pastorino, L.; Palombo, D.; Perego, P. Engineered $\mathrm{CaCO}_{3}$ nanoparticles with targeting activity: A simple approach for a vascular intended drug delivery system. Can. J. Chem. Eng. 2017, 95, 1683-1689. [CrossRef]

12. Lovelyn, C.; Attama, A.A. Current state of nanoemulsions in drug delivery. J. Biomater. Nanobiotechnol. 2011, 2, 626-639. [CrossRef]

13. Oumzil, K.; Ramin, M.A.; Lorenzato, C.; Hémadou, A.; Laroche, J.; Jacobin-Valat, M.J.; Mornet, S.; Roy, C.-E.; Kauss, T.; Gaudin, K.; et al. Solid lipid nanoparticles for image-guided therapy of atherosclerosis. Bioconj. Chem. 2016, 27, 569-575. [CrossRef]

14. Liu, J.; Gu, C.; Cabigas, E.B.; Pendergrass, K.D.; Brown, M.E.; Luo, Y.; Davis, M.E. Functionalized dendrimer-based delivery of angiotensin type 1 receptor siRNA for preserving cardiac function following infarction. Biomaterials 2013, 34, 3729-3736. [CrossRef]

15. Panda, V.S.; Naik, S.R. Cardioprotective activity of Ginkgo biloba phytosomes in isoproterenol-induced myocardial necrosis in rats: A biochemical and histoarchitectural evaluation. Exp. Toxicol. Pathol. 2008, 60, 397-404. [CrossRef]

16. Peters, D.; Kastantin, M.; Kotamraju, V.R.; Karmali, P.P.; Gujraty, K.; Tirrell, M.; Ruoslahti, E. Targeting atherosclerosis by using modular, multifunctional micelles. Proc. Natl. Acad. Sci. USA 2009, 106, 9815-9819. [CrossRef] [PubMed]

17. Almer, G.; Frascione, D.; Pali-Schöll, I.; Vonach, C.; Lukschal, A.; Stremnitzer, C.; Diesner, S.C.; Jensen-Jarolim, E.; Prassl, R.; Mangge, H. Interleukin-10: An anti-inflammatory marker to target atherosclerotic lesions via PEGylated liposomes. Mol. Pharm. 2013, 10, 175-186. [CrossRef] [PubMed]

18. Zachman, A.L.; Wang, X.; Tucker-Schwartz, J.M.; Fitzpatrick, S.T.; Lee, S.H.; Guelcher, S.A.; Skala, M.C.; Sung, H.J. Uncoupling angiogenesis and inflammation in peripheral artery disease with therapeutic peptide-loaded microgels. Biomaterials 2014, 35, 9635-9648. [CrossRef] 
19. Cheng, G.; Zhang, X.; Chen, Y.; Lee, R.J.; Wang, J.; Yao, J.; Zhang, Y.; Zhang, C.; Wang, K.; Yu, B. Anticancer activity of polymeric nanoparticles containing linoleic acid-SN38 (LA-SN38) conjugate in a murine model of colorectal cancer. Colloid. Surf. B 2019, 181, 822-829. [CrossRef]

20. Jana, U.; Mohanty, A.K.; Pal, S.L.; Manna, P.K.; Mohanta, G.P. Felodipine loaded PLGA nanoparticles: Preparation, physicochemical characterization and in vivo toxicity study. Nano Converg. 2014, 1, 1-10. [CrossRef]

21. Primard, C.; Poecheim, J.; Heuking, S.; Sublet, E.; Esmaeili, F.; Borchard, G. Multifunctional PLGA-based nanoparticles encapsulating simultaneously hydrophilic antigen and hydrophobic immunomodulator for mucosal immunization. Mol. Pharm. 2013, 10, 2996-3004. [CrossRef] [PubMed]

22. Gentile, P.; Nandagiri, V.; Pabari, R.; Daly, J.; Tonda-Turo, C.; Ciardelli, G.; Ramtoola, Z. Influence of parathyroid hormone-loaded PLGA nanoparticles in porous scaffolds for bone regeneration. Int. J. Mol. Sci. 2015, 16, 20492-20510. [CrossRef] [PubMed]

23. Chereddy, K.K.; Her, C.-H.; Comune, M.; Moia, C.; Lopes, A.; Porporato, P.E.; Vanacker, J.; Lam, M.C.; Steinstraesser, L.; Sonveaux, P.; et al. PLGA nanoparticles loaded with host defense peptide LL37 promote wound healing. J. Control. Release 2014, 194, 138-147. [CrossRef] [PubMed]

24. Feczkó, T.; Tóth, J.; Dósa, G.; Gyenis, J. Optimization of protein encapsulation in PLGA nanoparticles. Chem. Eng. Process. 2011, 50, 757-765. [CrossRef]

25. Liang, G.; Zhu, Y.; Sun, B.; Hu, F.; Tian, T.; Li, S.; Xiao, Z. PLGA-based gene delivering nanoparticle enhance suppression effect of miRNA in HePG2 cells. Nanoscale Res. Lett. 2011, 6, 1-9. [CrossRef] [PubMed]

26. Martins, C.; Sousa, F.; Araújo, F.; Sarmento, B. Functionalizing PLGA and PLGA derivatives for drug delivery and tissue regeneration applications. Adv. Healthc. Mater. 2018, 7. [CrossRef]

27. Kocbek, P.; Obermajer, N.; Cegnar, M.; Kos, J.; Kristl, J. Targeting cancer cells using PLGA nanoparticles surface modified with monoclonal antibody. J. Control. Release 2007, 120, 18-26. [CrossRef]

28. Huang, W.; Zhang, C. Tuning the size of poly(lactic-co-glycolic acid) (PLGA) nanoparticles fabricated by nanoprecipitation. Biotechnol. J. 2018, 13. [CrossRef]

29. Arpagaus, C. PLA/PLGA nanoparticles prepared by nano spray drying. J. Pharm. Investig. 2019, 49, 405-426. [CrossRef]

30. Cohen-Sela, E.; Chorny, M.; Koroukhov, N.; Danenberg, H.D.; Golomb, G. A new double emulsion solvent diffusion technique for encapsulating hydrophilic molecules in PLGA nanoparticles. J. Control. Release 2009, 133, 90-95. [CrossRef]

31. Streck, S.; Neumann, H.; Nielsen, H.M.; Rades, T.; McDowell, A. Comparison of bulk and microfluidics methods for the formulation of poly-lactic-co-glycolic acid (PLGA) nanoparticles modified with cell-penetrating peptides of different architectures. Int. J. Pharm. 2019, 1. [CrossRef] [PubMed]

32. Alshamsan, A. Nanoprecipitation is more efficient than emulsion solvent evaporation method to encapsulate cucurbitacin I in PLGA nanoparticles. Saudi Pharm. J. 2014, 22, 219-222. [CrossRef] [PubMed]

33. Campardelli, R.; Espirito Santo, I.; Albuquerque, E.C.; de Melo, S.V.; Della Porta, G.; Reverchon, E. Efficient encapsulation of proteins in submicro liposomes using a supercritical fluid assisted continuous process. J. Supercrit. Fluids 2016, 107, 163-169. [CrossRef]

34. Petersen, A.L.; Hansen, A.E.; Gabizon, A.; Andresen, T.L. Liposome imaging agents in personalized medicine. Adv. Drug Deliv. Rev. 2012, 64, 1417-1435. [CrossRef] [PubMed]

35. Swaminathan, J.; Ehrhardt, C. Liposomal delivery of proteins and peptides. Expert Opin. Drug Deliv. 2012, 9, 1489-1503. [CrossRef]

36. Maherani, B.; Arab-Tehrany, E.; Kheirolomoom, A.; Geny, D.; Linder, M. Calcein release behavior from liposomal bilayer; influence of physicochemical/mechanical/structural properties of lipids. Biochimie 2013, 95, 2018-2033. [CrossRef]

37. Movahedi, F.; Hu, R.G.; Becker, D.L.; Xu, C. Stimuli-responsive liposomes for the delivery of nucleic acid therapeutics. Nanomed Nanotechnol. 2015, 11, 1575-1584. [CrossRef]

38. Patil, Y.P.; Jadhav, S. Novel methods for liposome preparation. Chem. Phys. Lipids 2014, 177, 8-18. [CrossRef]

39. Akbarzadeh, A.; Rezaei-Sadabady, R.; Davaran, S.; Joo, S.W.; Zarghami, N.; Hanifehpour, Y.; Samiei, M.; Kouhi, M.; Nejati-Koshki, K. Liposome: Classification, preparation, and applications. Nanoscale Res. Lett. 2013, 8, 102. [CrossRef]

40. Khosravi-Darani, K.; Mozafari, M.R. Nanoliposome potentials in nanotherapy: A concise overview. J. Nanosci. Nanotechnol. 2010, 6, 3-13. 
41. Fornaguera, C.; Calderó, G.; Mitjans, M.; Vinardell, M.P.; Solans, C.; Vauthier, C. Interactions of PLGA nanoparticles with blood components: Protein adsorption, coagulation, activation of the complement system and hemolysis studies. Nanoscale 2015, 7, 6045-6058. [CrossRef] [PubMed]

42. Michanetzis, G.P.; Markoutsa, E.; Mourtas, S.; Missirlis, Y.F.; Antimisiaris, S.G. Hemocompatibility of amyloid and/or brain targeted liposomes. Future Med. Chem. 2019, 11, 693-705. [CrossRef] [PubMed]

43. Freytag, T.; Dashevsky, A.; Tillman, L.; Hardee, G.E.; Bodmeier, R. Improvement of the encapsulation efficiency of oligonucleotide-containing biodegradable microspheres. J. Control. Release 2000, 69, 197-207. [CrossRef]

44. Alex, R.; Bodmeier, R. Encapsulation of water-soluble drugs by a modified solvent evaporation method. I. Effect of process and formulation variables on drug entrapment. J. Microencapsul. 1990, 7, 347-355. [CrossRef]

45. Herrmann, J.; Bodmeier, R. Somatostatin containing biodegradable microspheres prepared by a modified solvent evaporation method based on W/O/W-multiple emulsions. Int. J. Pharm. 1995, 126, 129-138. [CrossRef]

46. Chen, L.Q.; Fang, L.; Ling, J.; Ding, C.Z.; Kang, B.; Huang, C.Z. Nanotoxicity of silver nanoparticles to red blood cells: Size dependent adsorption, uptake, and hemolytic activity. Chem. Res. Toxicol. 2015, 28, 501-509. [CrossRef]

Publisher's Note: MDPI stays neutral with regard to jurisdictional claims in published maps and institutional affiliations.

(C) 2020 by the authors. Licensee MDPI, Basel, Switzerland. This article is an open access article distributed under the terms and conditions of the Creative Commons Attribution (CC BY) license (http://creativecommons.org/licenses/by/4.0/). 